\title{
Nitric Oxide in Health and Physical Performance: Considering the Molecule 2 Nitrooxy Ethyl 2 Amino 3 Methylbutanoate
}

\author{
Richard J. Bloomer (Corresponding author) \\ Cardiorespiratory/Metabolic Laboratory, School of Health Studies \\ University of Memphis, Memphis, TN, USA \\ E-mail: rbloomer@memphis.edu
}

Received: June 30, 2015 Accepted: July 30, 2015

doi:10.5296/jbls.v7i2.9963 URL: http://dx.doi.org/10.5296/jbls.v7i2.9963

\begin{abstract}
Nitric oxide (NO) is an important signaling molecule that has received considerable attention in recent years for its beneficial impact on a variety of health related outcomes. The effects range from improving various aspects of circulatory health to aiding exercise performance. Although NO is produced naturally within the body, methods have been proposed to increase circulating NO within humans. Most notably, the performance of regular exercise, the use of pharmaceutical agents, and the use of nutritional ingredients has been studied. A newly developed molecule known as 2 nitrooxy ethyl 2 amino 3 methylbutanoate (VEENTM) is now being studied as a next generation $\mathrm{NO}^{\circ}$ agent. This paper discusses the importance of $\mathrm{NO}^{\circ}$ in human health, with a particular focus on methods to increase NO. Attention is given to VEEN $^{T M}$, highlighting the studies performed to date using this molecule.
\end{abstract}

Keywords: Nitric oxide, Blood pressure, Exercise, Health, Nutritional supplements

\section{Nitric Oxide Defined}

Nitric oxide (NO) is an important signaling molecule initially referred to as endothelium-derived relaxing factor (Furchgott and Zawadzki, 1980) and known to induce vasodilation (Collier and Vallance, 1989). Nitric oxide has multiple beneficial effects within the human body - in particular when present at low (nanomolar) concentrations. These include, but are not limited to decreased smooth muscle cell proliferation and platelet and leukocyte adhesion (Bian et al., 2008), regulation of neurotransmission (Thomas et al., 2008), regulation of immune defense (Tripathi, 2007), influence on excitation-contraction coupling and myofibrillar function (Sheffield-Moore et al., 2013), regulation of muscle hypertrophy 
(Leiter et al., 2012), and stimulation of satellite cells (Anderson, 2000).

The effect that has garnered the greatest interest over the past several years relates to the ability of NO to induce vasorelaxation of smooth muscle (Loscalzo, 2013). Theoretically, such vasorelaxation would enhance blood flow to specific body tissues, potentially resulting in a variety of cardiovascular benefits-including a reduction in blood pressure, a decrease in myocardial work, and an enhancement in sexual function. Increased blood flow may also provide an ergogenic benefit related to the performance of acute exercise bouts-as has been suggested in recent research focused on the ingestion of nitrates prior to exercise (Hoon et al., 2013; Ormsbee et al., 2013).

Although multiple methods have been proposed to increase circulating NO, this molecule is adequately synthesized within most humans by a family of enzymes known as nitric oxide synthases (Robinson et al., 2011), using a combination of the amino acid L-arginine, oxygen, and a variety of other cofactors. As stated, while relatively low concentrations of $\mathrm{NO}^{\circ}$ can impart multiple favorable effects on human health, very high concentrations of this molecule favor cell cycle arrest and programmed cell death (Napoli et al., 2013); the effect which may be dependent on the flux and concentration of $\mathrm{NO}^{\circ}$, the cell type, and the cellular redox status (Wang et al., 2010). This may be partly related to the potential formation of peroxynitrite, a harmful reactive nitrogen species which can be generated when NO interacts directly with the superoxide radical (Beckman and Koppenol, 1996).

Nitric oxide appears to function via both a cyclic guanosine monophosphate (cGMP) dependent and independent signaling cascade (Gewaltig and Kojda, 2002). It does so while functioning as a gaseous chemical compound-making oral ingestion near impossible; however, inhaled NO is widely used clinically (Bloch et al., 2007). In most circumstances, agents that are thought to stimulate the production of $\mathrm{NO}$ must be provided, rather than the actual NO itself. This has been an area of interest almost since the work of Furchgott and Zawadzki (1980) over 30 years ago. In fact, multiple lines of research related to NO have been ongoing, as evidenced by the naming of NO" as "molecule of the year" by Science magazine in 1992, and the awarding of the Nobel Prize in Physiology or Medicine in 1998 for work related to NO signaling within the cardiovascular system. Clearly, this molecule is of importance within the scientific and clinical community.

\section{Nitric Oxide, Health and Physical Performance}

The majority of NO research over the past few decades has been focused on how this molecule can improve certain aspects of human health. While many areas of study have been of interest to scientists, the topic of $\mathrm{NO}^{-}$-stimulated blood flow appears at the forefront. In fact, a PubMed search performed in June 2015 using the term "nitric oxide and blood flow" returned more than 11,000 articles. Indeed, this is a topic of intense interest.

Enhanced blood flow may be mechanistically responsible for improving certain aspects of cardiovascular health such as reducing blood pressure. In turn, a reduction in blood pressure may have a direct effect on improving heart health (e.g., reduction in myocardial work due to the decreased afterload), as well as reducing the potential for stroke. While not a "life or 
death" concern, improving blood flow to improve overall sexual function is also of great interest to individuals. Specifically, drugs that directly or indirectly impact NO bioavailability have been used widely to aid erectile function in men. Certain nutritional ingredients with a focus on the NO pathway have also been studied for purposes of improving sexual function (Estrada-Reyes et al., 2013).

\subsection{Physical Performance}

In relation to physical performance and sport supplementation, $\mathrm{NO}^{\circ}$ is of great interest for its potential effects on increasing blood flow-with a secondary effect in regulating muscle atrophy and hypertrophy. Bodybuilding and fitness magazines are inundated with pages of advertisements for $\mathrm{NO}^{-}$-stimulating nutritional supplements. Unfortunately, there are few studies (aside from those focused on nitrate ingestion) demonstrating benefits of these supplements on measures of exercise performance and related outcomes (e.g., muscle “pumps").

Acute exercise itself can induce an increase in NO (Bode-Böger et al., 1994a; Gilligan et al.., 1994; Hickner et al., 1997), likely owing to the shearing forces placed on the vasculature (Ramírez-Vélez et al., 2013) which provide the signal for endothelial cells to produce NO. Likewise, the performance of regular exercise leads to an increase in circulating $\mathrm{NO}^{\circ}$ metabolites nitrate $\left(\mathrm{NO}_{3}{ }^{-}\right)$and nitrite $\left(\mathrm{NO}_{2}{ }^{-}\right)$, suggesting an increase in NO production (Edwards et al., 2004; Poveda et al., 1997). Hence, individuals with the interest in increasing NO for purposes of improving overall health and physical performance would be best served by performing regular and strenuous exercise - in addition to paying close attention to other lifestyle factors known to influence NO production and availability (e.g., cessation of cigarette smoking, maintenance of an ideal body weight, reducing intake of saturated fat and sugar, maintaining low levels of oxidative stress) (Meldrum et al., 2012).

Although it remains to be directly demonstrated (Bloomer, 2010), the theoretical model suggests that increased NO will result in increased blood flow to working skeletal muscle during and following exercise. This, in turn, will result in increased oxygen and nutrient delivery (e.g., amino acids, fatty acids, glucose) which should aid both exercise performance and exercise recovery-ultimately leading to muscle hypertrophy.

Aside from NO regulation of exercise blood flow, several other mechanisms are involved with the redistribution of blood flow during and following exercise (Joyner and Wilkins, 2007; Tschakovsky and Joyner, 2008). These include muscle contraction-induced distortion of resistance vessels, flow mediated dilation, alterations in chemicals known to alter vessel diameter such as adenosine, endothelin, and prostacyclin, in addition to changes in muscle temperature, $\mathrm{pCO}_{2}, \mathrm{pO}_{2}$, and $\mathrm{pH}$. Hence, $\mathrm{NO}$ may play a smaller role in regulating exercise blood flow than many have been led to believe (Tschakovsky and Joyner, 2008).

\section{Proposed Methods to Increase Nitric Oxide}

As mentioned above, regular exercise has been demonstrated to increase NO production. In addition, alteration of whole food intake in favor of nitrate-rich vegetables and low saturated fat/low sugar foods may prove helpful (Bloomer et al., 2011; Trepanowski et al., 2012). In 
addition, a variety of pharmaceutical agents have been used in an attempt to alter NO production and/or availability. Lastly, certain nutritional ingredients have yielded positive outcomes (e.g., beetroot).

In relation to pharmaceuticals, several agents have been used with success to either increase NO biosynthesis or bioavailability, with the end result being enhanced vasodilatation (Burgaud et al., 2002). These agents include the sublingual and transdermal nitrates, intravenous propionyl-L-carnitine, intravenous L-arginine, and other medications used for the treatment of erectile dysfunction (e.g., phosphodiesterase-5 inhibitors). Related to the latter, although specifically prescribed for purposes of improving erectile function, evidence indicates the potential role of a phosphodiesterase-5 inhibitor (Sildenafil) to impact outcomes related to physical performance and adaptations to regular exercise (Hsu et al., 2006; Rinaldi et al., 2013; Sheffield-Moore et al., 2013). This fact suggests the likelihood that phosphodiesterase-5 inhibitors are now being used within the athletic doping world.

\subsection{Nutritional Ingredients}

If individuals are not interested in using pharmaceutical agents in an attempt to influence NO; they may opt for isolated nutritional ingredients that may have an effect. Although various nutritional ingredients have been studied for purposes of influencing NO' (e.g., citrulline, resveratrol, grape seed extract), only a few have a relatively large number of studies dedicated to their use in human subjects. These are discussed below.

Historically, the amino acid L-arginine has been suggested for use, as arginine is directly involved in the biosynthesis of NO. In addition, a specific form of carnitine known as propionyl L-carnitine or glycine propionyl L-carnitine (GPLC) has been used with success. Finally and most recently, beetroot juice and its active component, nitrate has been used to increase NO and improve associated parameters (e.g., blood pressure, exercise performance). The below text briefly discusses these ingredients.

\subsection{L-Arginine}

A review of dietary supplements marketed over the past several years which are designed to increase NO indicates that many products contain L-arginine as the chief ingredient - typically at a dosage of approximately 3 grams per serving. While the overall basis for arginine inclusion may seem justified, as arginine is the precursor to $\mathrm{NO}$ biosynthesis and has been associated with enhanced vasodilatation (Bode-Böger et al., 1994b; Giugliano et al., 1997), a careful review indicates that a relatively small oral dosage of L-arginine may provide little overall benefit.

Consider that the rationale for L-arginine inclusion is based largely on research using intravenous L-arginine, often at a dosage as high as 20 or 30 grams. Early studies involving direct comparisons between intravenous and oral L-arginine indicate no vasodilatory effect of oral L-arginine, which may be attributed to variability in oral L-arginine bioavailability (Bode-Böger et al., 1998) - possibly due to the fact that oral L-arginine intake is negatively influenced by extensive elimination due to intestinal arginase activity (Schwedhelm et al., 2008). In support of these findings, studies involving oral intake of L-arginine at dosages 
ranging from 10 to 20 grams indicate no benefit with regards to increasing circulating NO or, more importantly, impacting the more important end result of enhanced blood flow (Adams et al., 1995; Chin-Dusting et al., 1996). Finally, the possibility that L-arginine itself may not be the rate limiting component to NO biosynthesis must be considered (Kurz and Harrison, 1997). Rather, nitric oxide synthase enzymes may be most important. Hence, simply adding L-arginine at high dosages may provide little to no benefit if the enzymes involved in NO synthesis are not available at optimal activities to facilitate the formation of the molecule.

\subsection{Propionyl-L-Carnitine (and Glycine Propionyl-L-Carnitine)}

Propionyl-L-carnitine (PLC) has been used as a prescription drug in Europe, primarily for the treatment of intermittent claudication. At an intravenous dosage of 6 grams per day, PLC has been demonstrated to increase blood NO metabolites (Loffredo et al., 2007). Glycine Propionyl-L-carnitine is a molecular bonded form of PLC and the amino acid glycine, sold as a dietary ingredient. Oral intake of GPLC at a dosage of 4.5 grams per day results in increased plasma $\mathrm{NO}_{3}{ }^{-}+\mathrm{NO}_{3}{ }^{-}$. This has been reported in previously sedentary men and women following an eight week intervention (Bloomer et al., 2009) and in resistance trained men following a four week intervention (Bloomer et al., 2007). The mechanism of action for this apparent increase in NO with PLC and GPLC appears mediated by a decrease in NADPH oxidase activation (Pignatelli et al., 2003). It is known that NADPH oxidase can lead to superoxide radical generation (Zalba et al., 2001), which can then interact with NO to form peroxynitrite (Beckman et al., 1996) and decrease NO availability. Propionyl-L-carnitine can also increase endothelial nitric oxide synthase (eNOS) (de Sotomayor et al., 2007), leading to increased NO production.

\subsection{Beetroot Juice and Nitrate}

An emerging area of investigation is the study of beetroot juice (and the active ingredient contained within the beetroot juice-nitrate) to aid exercise performance and associated parameters (Hoon et al., 2013; Ormsbee et al., 2013). Recent reviews of literature indicate that approximately 60 studies have now been performed focused on beetroot juice, beetroot, or sodium nitrate to improve certain aspects of aerobic or anaerobic exercise performance, as well as mechanisms responsible for the ergogenic effect. One such mechanism is enhanced NO production and/or bioavailability. Based on the volume of research performed to date using nitrate (either as a component of beetroot or as sodium nitrate), this may be the most promising nutritional ingredient available at the present time for purposes of enhancing $\mathrm{NO}^{\circ}$ and yielding the desired effects of $\mathrm{NO}^{\circ}$ elevation.

\section{2 Nitrooxy Ethyl 2 Amino 3 Methylbutanoate (Veen ${ }^{\mathrm{MM}}$ )}

While not technically a pharmaceutical agent or a nutritional ingredient, a new molecule known as "2 nitrooxy ethyl 2 amino 3 methylbutanoate" has been developed with the objective of delivering NO to the circulation and enhancing health and physical performance. This molecule, trademarked as VEENTM (Smartek International), has a mechanism of action that is proposed to differ from other NO stimulators. Specifically, VEENTM does not provide precursor amino acids or other agents targeting increased NO biosynthesis (such as other 


\section{Macrothink}

Journal of Biology and Life Science

ISSN 2157-6076

2016, Vol. 7, No. 2

nutritional ingredients). Nor does VEENTM seek to inhibit the degradation of NO in order to prolong the effects (such as medications used for erectile dysfunction). Rather, VEEN ${ }^{\mathrm{TM}}$ is claimed to deliver actual NO to the circulation.

Within cells, the physiological effects of VEENTM appear related to a dual phase metabolism of the molecule. The first phase comprises the carboxylesterase cleavage of the valine from the nitrooxy ethyl alcohol, while the second phase involves the glutathione transferase regulated metabolism of nitrooxy ethyl alcohol in the cytosol of endothelial cells to NO. Variance in subject response to VEENTM treatment may be partly explained through a genotypic difference in carboxylesterase 2 activity (Wu et al., 2004), which would limit the first cleavage reaction to produce the active intermediate. In addition, a laminar flow feedback mechanism (Chen et al., 2003) of glutathione transferase in the endothelial cells may contribute in the second phase reaction. Additional research is needed to confirm these hypotheses.

Presently, in human subjects the VEENTM can be delivered either as a sublingual fast-dissolve tablet or as a transdermal rub-on gel. Both delivery systems have been studied recently, as detailed in the text below. In animal research, the VEEN ${ }^{\mathrm{TM}}$ molecule has been delivered via inhalation as well. This is also discussed in the relevant section below. In terms of safety, the VEEN $^{\mathrm{TM}}$ molecule has recently been investigated extensively by AIBMR Life Sciences, Inc. and has been granted self-determination Generally Recognized as Safe (GRAS) status. A schematic of the potential mechanisms and impact of VEENTM in human physiology is presented in Figure 1.

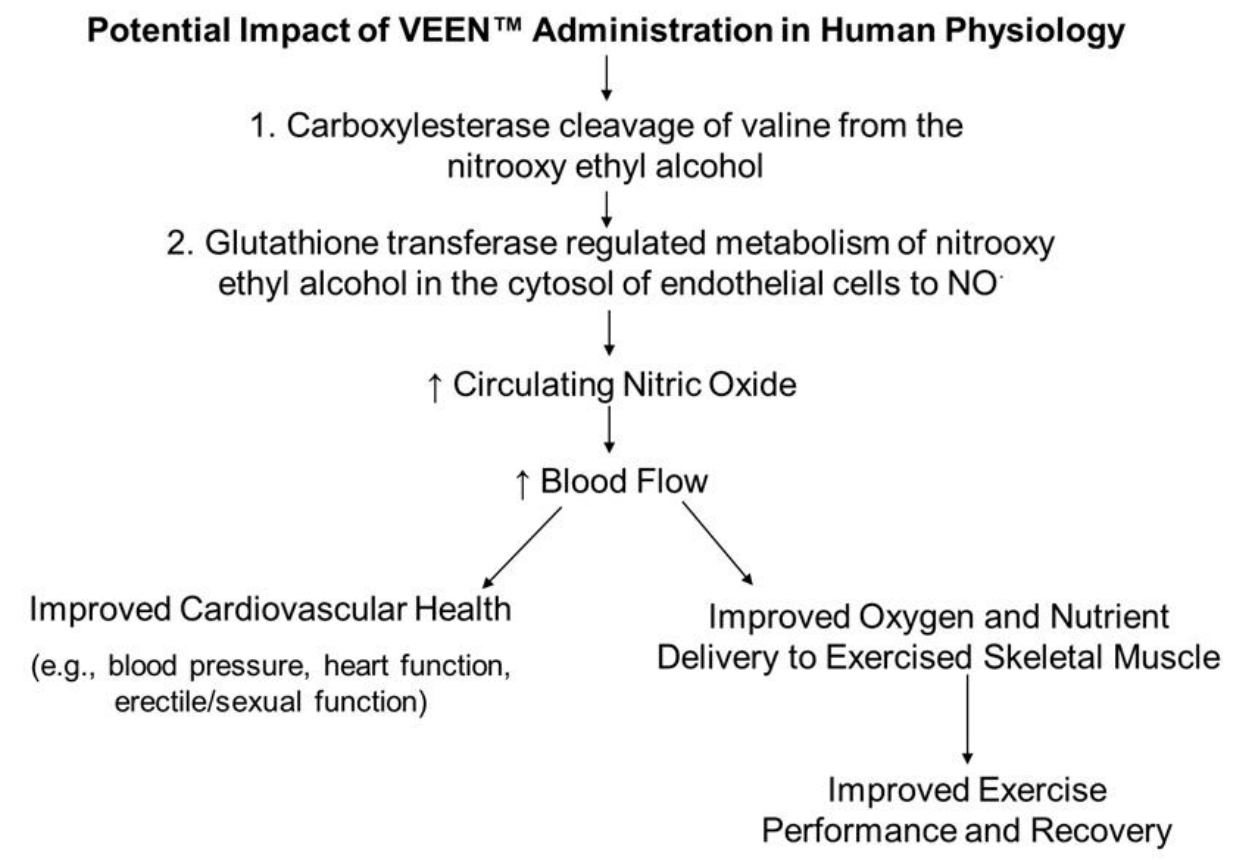

Figure 1. The Potential Impact of VEENTM Administration in Human Physiology 


\subsection{Human Studies of VEEN ${ }^{\mathrm{TM}}$}

In the first human study of VEEN ${ }^{\mathrm{TM}}, 10$ resistance-trained men received either a placebo or the VEEN ${ }^{\mathrm{TM}}$ fast-dissolved sublingual tablets on two separate occasions using a randomized, cross-over design (Bloomer et al., 2010). Blood samples were taken before and at 5, 15, 30, and 60 minutes after complete breakdown of the supplement or placebo. An approximate 7\% increase in circulating nitrate/nitrite was noted at the 15 minute post-ingestion period for subjects when ingesting the VEEN ${ }^{\mathrm{TM}}$ tablets. Heart rate and blood pressure were measured at the times indicated above and noted to be nearly identical between the VEEN ${ }^{\mathrm{TM}}$ and placebo conditions, and relatively unchanged across time. No measures of physical performance were obtained in that study.

With consideration that oral delivery leads to systemic uptake of the molecule and potential for compartmentalization into specific tissues, the VEEN ${ }^{\mathrm{TM}}$ has also been imbedded within a topical, gel-based delivery system. The gel is applied to the skin and rubbed on; in much the same way as lotion would be applied. Using this gel-based delivery technology, a sample of 14 resistance-trained men received either a placebo gel or the VEEN ${ }^{\mathrm{TM}}$ gel to use for a period of seven days (with 7-10 days between each condition) using a randomized, cross-over design (Bloomer et al., 2012). Subjects applied the gel to their upper and lower arms each day and then reported to the lab to perform assessments of arm isometric force and muscular endurance ( 3 sets to fatigue using 80,65 , and $50 \%$ of 1 repetition maximum [1RM]: total of 9 sets). Subjects' heart rate and perceived exertion related to the exercise were measured after each set and were nearly identical between conditions; with the lack of change in heart rate highlighting the non-stimulatory nature of the molecule. While no performance measure was noted to be statistically significant, in 8 subjects who were noted as being "responders" to the VEEN ${ }^{\mathrm{TM}}$ treatment, $19.9 \%$ more repetitions were performed when using a load of $50 \%$ of 1RM. In 9 of the 14 subjects tested, higher blood NO metabolites were noted with greater total repetition number, suggesting the potential involvement of NO in exercise performance. Future experiments are needed to confirm this hypothesis.

Most recently, VEEN ${ }^{\mathrm{TM}}$ or placebo was provided to 15 healthy men in a fast-dissolved sublingual tablet on two separate occasions using a randomized, cross-over design (Bloomer et al., 2015). Subjects received their assigned condition before performing two, two-minute sets of sit-up exercise (exercise sets performed 20 minutes apart). Heart rate, as well as systolic (SBP) and diastolic (DBP) blood pressure were measured before and for 20 minutes following each set of exercise. In addition, blood was collected and analyzed for nitrate/nitrite. Results indicated that heart rate was unaffected by treatment. However, SBP and DBP was lower with VEEN ${ }^{\mathrm{TM}}$ as compared to placebo, in particular during the 20 minute recovery period following set two of exercise. Nitrate/nitrite was increased approximately $10 \%$ above baseline with VEEN ${ }^{\mathrm{TM}}$, suggesting a possible impact of NO on blood pressure regulation. Interestingly, the impact of $\mathrm{VEEN}^{\mathrm{TM}}$ on blood pressure appears to be in response to the acute elevation in blood pressure. That is, with relatively stable blood pressure, VEEN $^{\mathrm{TM}}$ does not appear to induce any further reduction. However, when blood pressure is acutely elevated, the molecule appears to be activated and leads to a compensatory reduction in blood pressure. Further research is needed to extend these initial findings. 


\subsection{Animal Studies of VEEN ${ }^{\mathrm{TM}}$}

A total of four animal studies using VEEN ${ }^{\mathrm{TM}}$ have been conducted to date. Two studies involving rats and two studies involving a ferret model have been completed (unpublished findings). In one rat study, the VEEN ${ }^{\mathrm{TM}}$ was delivered orally for a period of 90 days. Findings after 90 days of treatment indicated slight changes in the mean percentage of reticulocytes and organ weight (spleen, kidney, liver) in both male and female animals, with slight changes in reticulocytes and spleen weight relative to body weight in male animals only. Based on these findings, the study investigators concluded that the No Observed Adverse Effect Level (NOAEL) was $1000 \mathrm{mg} / \mathrm{kg}$ body weight/day for both male and female rats.

When using a transdermal cream for a period of 10 days and compared against other antibiotic creams in the treatment of lesch in rats, the VEEN ${ }^{\mathrm{TM}}$ cream was noted to be more effective than all treatments except for one (a double antibiotic cream). Moreover, no adverse effects were observed.

The studies in the ferret model involved an investigation of the aerosolized VEENTM molecule to impact H1N1 infected animals. In both studies, animals were treated with either the VEENTM or vehicle (nebulized saline) twice daily for 5 days. Results indicated that the molecule was safe, with no reported adverse effects. In addition, blood nitrite levels were measured and noted to be elevated in animals treated with the VEENTM molecule.

\subsection{Future Studies with VEEN ${ }^{\mathrm{TM}}$}

As with all new developments and discoveries, well-designed research studies are needed to explore their potential applications. In three human studies on normotensive individuals, VEEN $^{\mathrm{TM}}$ has been shown to be a novel NO donor and vasodilator; however these studies have been relatively small in size and scope. Additional human studies are needed to determine the influence of VEEN ${ }^{\mathrm{TM}}$ on aspects of human health, including blood pressure reduction, sexual function (and associated parameters), and physical performance in relevant populations. Select subject populations should be chosen for such work (e.g., those with hypertension, men with erectile dysfunction, recreationally active exercise enthusiasts).

\section{Conclusion}

Nitric oxide is an important signaling molecule that has great potential as a therapeutic aid. While lifestyle factors such as performance of regular exercise, maintenance of ideal body weight, ingestion of a healthy diet, and cessation of cigarette smoking are paramount if attempting to maximize circulating $\mathrm{NO}^{\circ}$, adjunctive therapy is available in the form of pharmaceutical and nutritional agents. While additional research is certainly needed, the VEEN $^{\mathrm{TM}}$ molecule may have potential as a next generation NO agent. Ongoing and future research should provide more evidence regarding the potential application of this molecule and nutritional agents such as nitrate to aid human health and performance.

\section{References}

Adams, M. R., Forsyth, C. J., Jessup, W., Robinson, J., \& Celermajer, D. S. (1995). Oral arginine inhibits platelet aggregation but does not enhance endothelium-dependent dilation in 
healthy young men. J. Amer. Col. Cardiology, 26(4), 1054-1061. http://dx.doi.org/10.1016/0735-1097(95)00257-9

Anderson, J. E., (2000). A role for nitric oxide in muscle repair: nitric oxide-mediated activation of muscle satellite cells. Mol. Biol. Cell, 11(5), 1859-1874. http://dx.doi.org/10.1091/mbc.11.5.1859

Beckman, J. S, \& Koppenol, W. H. (1996). Nitric oxide, superoxide, and peroxynitrite: the good, the bad, and ugly. Am. J. Physiol. 271(5 Pt 1), C1424-1437.

Bian, K, Doursout, M. F., \& Murad, F. (2008.). Vascular system: role of nitric oxide in cardiovascular diseases. J. Clin. Hypertens. (Greenwich). 10(4), 304-310. http://dx.doi.org/10.1111/j.1751-7176.2008.06632.x

Bloch, K. D., Ichinose, F, Roberts, J. D. Jr, \& Zapol, W. M. (2007). Inhaled NO as a therapeutic agent. Cardiovasc Res. Jul 15, 75(2), 339-48. http://dx.doi.org/10.1016/j.cardiores.2007.04.014

Bloomer, R. J., Smith, W. A., \& Fisher-Wellman, K. H. (2007). Glycine propionyl-L-carnitine increases plasma nitrate/nitrite in resistance trained men. J. Int. Soc. Sports Nutr. 4(1), 22. http://dx.doi.org/10.1186/1550-2783-4-22

Bloomer, R. J., Tschume, L. C., \& Smith, W. A. (2009). Glycine propionyl-L-carnitine modulates lipid peroxidation and nitric oxide in human subjects. Int. J. Vitam. Nutr. Res. May, 79(3), 131-41. http://dx.doi.org/10.1024/0300-9831.79.3.131

Bloomer, R. J., Williams, S. A., Canale, R. E., Farney, T. M., Kabir, M. M. (2010). Acute effect of nitric oxide supplement on blood nitrate/nitrite and hemodynamic variables in resistance trained men. $J$ Strength Cond Res. Oct, 24(10), 2587-92. http://dx.doi.org/10.1519/JSC.0b013e3181e382c0

Bloomer, R. J. (2010). Nitric Oxide Supplements for Sports. Strength and Conditioning Journal. 32(2), 14-20. http://dx.doi.org/10.1519/SSC.0b013e3181bdaf89

Bloomer, R. J., Kabir, M. M., Trepanowski, J. F., Canale, R. E., Farney, T. M. (2011). A 21 day Daniel Fast improves selected biomarkers of antioxidant status and oxidative stress in men and women. Nutr Metab (Lond). Mar 18, 8-17. http://dx.doi.org/10.1186/1743-7075-8-17

Bloomer, R. J., Alleman, R. J. Jr, Cantrell, G. S., Farney, T. M., Schilling, B. K. (2012), Effects of 2-nitrooxy ethyl 2-amino 3-methylbutanoate gel on resistance exercise performance and blood nitrate/nitrite in resistance trained men. J Strength Cond Res. Jun, 26(6), 1680-7. http://dx.doi.org/10.1519/JSC.0b013e318236d081

Bloomer, R. J., Moran. R., MacDonnchadh, J., Lee, S.,R., Farber, M. (2016), Impact of 2-nitrooxy-ethyl-2-amino-3-methylbutanoate on blood pressure and plasma nitrate/nitrite following acute exercise in normotensive men. Med Res Archives, 3(6), 1-13. http://dx.doi.org/10.18103/mra.v3i6.480 
Bode-Böger, S. M., Boger, R. H., Scroder, E. P., \& Frolich, J. C. (1994a). Exercise increases systemic nitric oxide production in men. J. Cardiovasc. Risk. 1, 173-178. http://dx.doi.org/10.1177/174182679400100212

Bode-Böger, S. M., Böger, R. H., Creutzig, A., Tsikas, D., Gutzki, F. M., Alexander, K., \& Frölich, J. C. (1994b). L-arginine infusion decreases peripheral arterial resistance and inhibits platelet aggregation in healthy subjects. Clin. Sci. (Lond). 87(3), 303-310. http://dx.doi.org/10.1042/cs0870303

Bode-Böger, S. M., Boger, R. H., Galland, A., Tsikas, D., \& Frolich, J. (1998). L-arginine-induced vasodilatation in healthy humans: pharmacokinetic-pharmacodynamic $\begin{array}{lllll}\text { relationship. } \quad B r . & \text { J. } & \text { Clin. } & \text { Pharmacol. } & \text { 46(5), }\end{array}$ http://dx.doi.org/10.1046/j.1365-2125.1998.00803.x

Burgaud, J. L., Ongini, E., \& Del Soldato, P. (2002). Nitric oxide-releasing drugs: a novel class of effective and safe therapeutic agents. Ann. NY Acad. Sci. 962, 360-371. http://dx.doi.org/10.1111/j.1749-6632.2002.tb04080.x

Chen, X. L., Varner, S. E., Rao, A. S., Grey, J. Y., Thomas, S., Cook, C. K., Wasserman, M. A., Medford, R. M., Jaiswal, A. K., \& Kunsch, C. (2003). Laminar flow induction of antioxidant response element-mediated genes in endothelial cells. A novel anti-inflammatory mechanism. J. Biol. Chem, 278, 703-711. http://dx.doi.org/10.1074/jbc.M203161200

Chin-Dusting, J. P., Alexander, C. T., Arnold, P. J., Hodgson, W. C., Lux, A. S., \& Jennings, G. L. (1996). Effects of in vivo and in vitro L-arginine supplementation on healthy human $\begin{array}{lllll}\text { vessels. } & \text { J. } & \text { Cardiovasc. } & \text { Pharmacol. } & \text { 28(1), }\end{array}$ http://dx.doi.org/10.1097/00005344-199607000-00023

Collier, J, \& Vallance, P. (1989). Endothelium-derived relaxing factor is an endogenous vasodilator in man. Br J Pharmacol. Jul, 97(3), 639-41. http://dx.doi.org/10.1111/j.1476-5381.1989.tb11998.x

Collier, J., \& Vallance, P. (1991). Physiological importance of nitric oxide. BMJ, 32, 1289-1290. http://dx.doi.org/10.1136/bmj.302.6788.1289

De Sotomayor, M. A, Mingorance, C, Rodriguez-Rodriguez, R., Marhuenda, E., \& Herrera, M. D. (2007). 1-carnitine and its propionate: improvement of endothelial function in SHR through superoxide dismutase-dependent mechanisms. Free Radic. Res. 41(8), 884-891. http://dx.doi.org/10.1080/10715760701416467

Edwards, D. G., Schofield, R. S., Lennon, S. L., Pierce, G. L., Nichols, W. W., \& Braith, R. W: (2004). Effect of exercise training on endothelial function in men with coronary artery disease. Am. J. Cardiol. 93(5), 617-620. http://dx.doi.org/10.1016/j.amjcard.2003.11.032

Estrada-Reyes, R., Carro-Juárez, M., Martínez-Mota, L. (2013). Pro-sexual effects of Turnera diffusa Wild (Turneraceae) in male rats involves the nitric oxide pathway. $J$ Ethnopharmacol. Mar 7, 146(1), 164-72. http://dx.doi.org/10.1016/j.jep.2012.12.025 
Furchgott, R. F., \& Zawadzki, J. V. (1980). The obligatory role of the endothelium in the relaxation of arterial smooth muscle by acetylcholine. Nature, 288, 373-376. http://dx.doi.org/10.1038/288373a0

Gewaltig, M. T., Kojda, G. (2002). Vasoprotection by nitric oxide: mechanisms and therapeutic potential. Cardiovasc Res. Aug 1, 55(2), 250-60. http://dx.doi.org/10.1016/S0008-6363(02)00327-9

Gilligan, D. M., Panza, J. A., Kilcoyne, C. M., Waclawiw, M. A., Casino, P. R., \& Quyyumi, A. A. (1994). Contribution of endothelium-derived nitric oxide to exercise-induced vasodilatation. Circulation, 90, 2853-2858. http://dx.doi.org/10.1161/01.CIR.90.6.2853

Giugliano, D., Marfella, R., Verrazzo, G., Acampora, R., Coppola, L., Cozzolino, D., \& D'Onofrio, F. (1997). The vascular effects of L-Arginine in humans. The role of endogenous insulin. J. Clin. Invest. 99(3), 433-438. http://dx.doi.org/10.1172/JCI119177

Hickner, R. C., Fisher, J. S, Ehsani, A. A., \& Kohrt, W. M. (1997). Role of nitric oxide in skeletal muscle blood flow at rest and during dynamic exercise in humans. Am. J. Physiol. 273(1 Pt 2), H405-410.

Hoon, M. W., Johnson, N. A., Chapman, P. G., Burke, L. M. (2013). The effect of nitrate supplementation on exercise performance in healthy individuals: a systematic review and meta-analysis. Int $J$ Sport Nutr Exerc Metab. Oct, 23(5), 522-32. http://dx.doi.org/10.1123/ijsnem.23.5.522

Hsu, A. R., Barnholt, K. E., Grundmann, N. K., Lin, J. H., McCallum, S. W., \& Friedlander, A. L. (2006). Sildenafil improves cardiac output and exercise performance during acute hypoxia, but not normoxia. J. Appl. Physiol, 100(6), 2031-40. http://dx.doi.org/10.1152/japplphysiol.00806.2005

Joyner, M. J., \& Wilkins, B. W. (2007). Exercise hyperaemia: is anything obligatory but the hyperaemia? J. Physiol, 583(Pt 3), 855-860. http://dx.doi.org/10.1113/jphysiol.2007.135889

Kurz, S., \& Harrison, D. G. (1997). Insulin and the arginine paradox. J. Clin. Invest, 99, 369-370. http://dx.doi.org/10.1172/JCI119166

Leiter, J. R., Upadhaya, R., Anderson, J. E. (2012). Nitric oxide and voluntary exercise together promote quadriceps hypertrophy and increase vascular density in female 18-mo-old mice. Am J Physiol Cell Physiol. May 1, 302(9), C1306-15. http://dx.doi.org/10.1152/ajpcell.00305.2011

Loffredo, L., Marcoccia, A., Pignatelli, P., Andreozzi, P., Borgia, M. C., Cangemi, R., Chiarotti, F., \& Violi, F. (2007). Oxidative-stress-mediated arterial dysfunction in patients with peripheral arterial disease. Eur. Heart J. 28(5), 608-612. http://dx.doi.org/10.1093/eurheartj/ehl533

Loscalzo, J. (2013). The identification of nitric oxide as endothelium-derived relaxing factor. Circ Res. Jul 5, 113(2), 100-3. http://dx.doi.org/10.1161/CIRCRESAHA.113.301577 
Meldrum, D. R., Gambone, J. C., Morris, M. A., Esposito, K., Giugliano, D., Ignarro, L. J. (2012). Lifestyle \& metabolic approaches to maximizing erectile and vascular health. Int $J$ Impot Res. Mar-Apr, 24(2), 61-8. http://dx.doi.org/10.1038/ijir.2011.51

Napoli, C., Paolisso, G., Casamassimi, A., Al-Omran, M., Barbieri, M., Sommese, L., Infante, T., Ignarro, L. J. (2013). Effects of nitric oxide on cell proliferation: novel insights. J Am Coll Cardiol. Jul 9, 62(2), 89-95. http://dx.doi.org/10.1016/j.jacc.2013.03.070

Ormsbee, M. J., Lox, J., \& Arciero, P. J. (2013). Beetroot juice and exercise performance. Nutrition and Dietary Supplements., 5, 27-35. http://dx.doi.org/10.2147/NDS.S52664

Pignatelli, P., Lenti, L., Sanguigni, V., Frati, G., Simeoni, I., Gazzaniga, P. P., Pulcinelli, F. M., \& Violi, F. (2003). Carnitine inhibits arachidonic acid turnover, platelet function, and oxidative stress. Am. J. Physiol. Heart Circ. Physiol. 284(1), H41-48. http://dx.doi.org/10.1152/ajpheart.00249.2002

Poveda, J. J., Riestra, A., Salas, E., Cagigas, M. L., Lopez-Somoza, C., Amado, J. A., \& Berrazueta, J. R. (1997). Contribution of nitric oxide to exercise-induced changes in healthy volunteers: effects of acute exercise and long-term physical training. Eur. J. Clin. Invest. 27(11), 967-971. http://dx.doi.org/10.1046/j.1365-2362.1997.2220763.x

Ramírez-Vélez, R., Bustamante, J., Czerniczyniec, A., Aguilar, de Plata, A. C., \& Lores-Arnaiz, S. (2013). Effect of Exercise Training on Enos Expression, NO Production and Oxygen Metabolism in Human Placenta. PLoS One. Nov 14, 8(11), e80225. http://dx.doi.org/10.1371/journal.pone.0080225

Rinaldi, B., Donniacuo, M., Sodano, L., Gritti, G., Signoriello, S., Parretta, E., Berrino, L., Urbanek, K., Capuano, A., \& Rossi, F. (2013). Effects of sildenafil on the gastrocnemius and cardiac muscles of rats in a model of prolonged moderate exercise training. PLoS One. Jul 29, 8(7), e69954. http://dx.doi.org/10.1371/journal.pone.0069954

Robinson, M. A., Baumgardner, J. E., Otto, C. M. (2011). Oxygen-dependent regulation of nitric oxide production by inducible nitric oxide synthase. Free Radic Biol Med. Dec 1, 51(11), 1952-65. http://dx.doi.org/10.1016/j.freeradbiomed.2011.08.034

Schwedhelm, E., Maas, R., Freese, R., Jung, D., Lukacs, Z., Jambrecina, A., Spickler, W., Schulze, F., \& Böger, R. H. (2008). Pharmacokinetic and pharmacodynamic properties of oral L-citrulline and L-arginine: impact on nitric oxide metabolism. Br. J. Clin. Pharmacol, 65(1), 51-59. http://dx.doi.org/10.1111/j.1365-2125.2007.02990.x

Sheffield-Moore, M., Wiktorowicz, J. E., Soman, K. V., Danesi, C. P., Kinsky, M. P., Dillon, E. L., ... (2013). Sildenafil increases muscle protein synthesis and reduces muscle fatigue. Clin Transl Sci. Dec, 6(6), 463-8. http://dx.doi.org/10.1111/cts.12121

Thomas, D. D., Ridnour, L. A., Isenberg, J. S., Flores-Santana, W., Switzer, C. H., Donzelli, S., Hussain, P., Vecoli, C., Paolocci, N., Ambs, S., Colton, C. A., Harris, C. C., Roberts, D. D., $\&$ Wink, D. A. (2008). The chemical biology of nitric oxide: implications in cellular signaling. Free Radic. Biol. Med. 45(1), 18-31. http://dx.doi.org/10.1016/j.freeradbiomed.2008.03.020 


\section{Macrothink}

Journal of Biology and Life Science ISSN 2157-6076 2016, Vol. 7, No. 2

Trepanowski, J. F., Kabir, M. M., Alleman, R. J., \& Jr, Bloomer, R. J. (2012). A 21-day Daniel fast with or without krill oil supplementation improves anthropometric parameters and the cardiometabolic profile in men and women. Nutr Metab (Lond). Sep 13, 9(1), 82. http://dx.doi.org/10.1186/1743-7075-9-82

Tripathi, P. (2007). Nitric oxide and immune response. Indian J Biochem Biophys. Oct, 44(5), 310-9.

Tschakovsky, M. E., \& Joyner, M. J. (2008). Nitric oxide and muscle blood flow in exercise. Appl. Physiol. Nutr. Metab. 33(1), 151-161. http://dx.doi.org/10.1139/H07-148

Wang, Y., Chen, C., Loake, G. J., Chu, C. (2010). Nitric oxide: promoter or suppressor of programmed cell death? Protein Cell. Feb, 1(2), 133-42.

Wu, M. H., Chen, P., Wu, X., Liu, W., Strom, S., Das, S., Cook, E. H., Jr, Rosner, G. L., \& Dolan, M. E. (2004). Determination and analysis of single nucleotide polymorphisms and haplotype structure of the human carboxylesterase 2 gene. Pharmacogenetics, 14, 595-605. http://dx.doi.org/10.1097/00008571-200409000-00004

Zalba, G., San, Jose, G, Moreno, M. U., Fortuno, M. A., Fortuno, A., Beaumont, F. J., \& Diez, J. (2001). Oxidative stress in arterial hypertension: role of NAD(P)H oxidase. Hypertension, 38(6), 1395-1399. http://dx.doi.org/10.1161/hy1201.099611

\section{Copyright Disclaimer}

Copyright for this article is retained by the author(s), with first publication rights granted to the journal.

This is an open-access article distributed under the terms and conditions of the Creative Commons Attribution license (http://creativecommons.org/licenses/by/3.0/). 